\title{
Oral health knowledge and behaviour among patient in supportive periodontal care in Sarawak
}

\author{
Mohamad Adib Jaafar ${ }^{*}$, Chen Hui Ling 2 , Aisah Ahmad ${ }^{2}$ \\ ${ }^{1}$ Periodontal Specialist Unit of Sibu Jaya, Sibu Jaya Dental Clinic, Ministry of Health Malaysia, Sibu, Sarawak. \\ ${ }^{2}$ Periodontal Specialist Unit of Jalan Masjid, Polyclinic Jalan Masjid, Ministry of Health Malaysia, Kuching, \\ Sarawak
}

\begin{abstract}
After completing the active phase of periodontal therapy, supportive periodontal care is required to maintain periodontal health. Patient knowledge and awareness are key to periodontal therapy's success, and the study aims to provide baseline data among supportive periodontal care patients in Sarawak. Questionnaires were distributed among patients at two periodontal clinics. Out of 80 responses, $31.3 \%$ of respondents believed they had a good-excellent level of periodontal health. 41.3\% felt satisfied with their current periodontal condition. 81.3\% understood what dental plaque was, $92.5 \%$ knew its role in the aetiology of gingival disease, and $93.8 \%$ knew it can be controlled with good oral hygiene care. $91.3 \%$ of them were aware that; gingival bleeding indicated the presence of periodontal disease, the disease can cause mobile teeth if untreated, and it can be prevented by having regular maintenance. Only $45 \%$ were aware that the disease is not 'curable.' Concerning behaviour, $98.8 \%$ brushed teeth at least twice daily and used dental floss (43.7\%), interdental brush (65\%), and mouthwash (52.5\%). In the case of gingival bleeding, $70 \%$ will continue brushing their teeth, and $36.3 \%$ will only use a mouth rinse. $37.5 \%$ will attend the appointment if pain arises, and $38.8 \%$ believed that a general dentist can sufficiently provide supportive periodontal care. In conclusion, there was inadequate knowledge of periodontitis's curative nature and a lack of understanding of the importance of specialist care's regular follow-up. It is important to reinforce oral health education at SPC.
\end{abstract}

Received:

8 December 2020

Revised:

6 January 2021

Accepted:

13 January 2021

Published Online:

28 February 2021

\section{How to cite this article:}

Jaafar, M. A., Chen , H. L., \& Ahmad, A. Oral health knowledge and behaviour among patient in supportive periodontal care in Sarawak. IIUM Journal of Orofacial and Health Sciences, 2(1), 26-36. https://doi.org/10.31436/ijoh $\underline{\text { s.v2i1.59 }}$

\section{Article DOI:}

https://doi.org/10.31436/ijohs $\underline{\mathrm{v} 2 \mathrm{i} 1.59}$

\section{Corresponding author:}

\section{Address:}

Periodontal Specialist Unit of Sibu Jaya, Sibu Jaya Dental Clinic, Ministry of Health Malaysia, Sibu, Sarawak.

\section{Email address:}

mohamad.adib@moh.gov.my madibjaafar@gmail.com

Keywords: supportive periodontal care, periodontitis, knowledge, behaviour.

\section{Introduction}

Periodontal disease is defined by pathologic loss of the periodontal ligament and alveolar bone (Slots, 2017). It is one of the main reasons for tooth loss in adults and is linked to systemic diseases such as atherosclerosis, cerebral ischemia, and diabetes (Linden et al., 2013). Advanced periodontal disease with deep pockets of $6 \mathrm{~mm}$ or more, affected about $10 \%$ to $15 \%$ of adults worldwide and described that it contributes significantly to the global burden of oral disease (Petersen \& Ogawa, 2005). In Malaysia, we observed a rise in advanced periodontitis prevalence, with only $6 \%$ in 1990 up to $18.2 \%$ in 2010 (Mohd Dom et al., 2016). 
In general, periodontal treatment can be divided into three phases: non-surgical, surgical, and maintenance or supportive periodontal care (SPC). The first two phases (non-surgical and surgical) aim to reduce the bacterial load through debridement and correction of the soft and hard tissue defect of tooth-supporting structures that will enable the patient to perform better oral hygiene care. Once the condition has improved and stabilised, the patient will be shifted into the last phase (SPC) to maintain the state of healthy and stable periodontal tissue (Tonetti et al., 1998). Under SPC, patients are required to attend a specialist clinic between 3 to 6 months annually, depending on the complexity of their periodontal status (Axelsson et al., 2004). Typically SPC includes an update of the medical and dental histories, dental and periodontal evaluation, removal of bacterial plaque and calculus supra and subgingivally, debridement if indicated, and a review of the patient's plaque removal efficacy (Leavy \& Robertson, 2018). Within that gap of 3 to 6 months, it is crucial for the patient to selfmaintain their oral hygiene care at home to prevent the disease's recurrence. Selfmaintaining care, such as tooth brushing twice a day, with interdental cleaning, has been shown to effectively reduce plaque and gingival inflammation (Yaacob et al., 2014). Regular interdental cleaning has also been shown to improve periodontal health (Jackson et al., 2006).

However, studies have shown that the degree of compliance with SPC has been insufficient (Delatola et al., 2014; Ojima et al., 2001). Patient compliance with SPC is a complex issue, and one of these factors is the patient's knowledge and awareness (Kopp et al., 2017). A study done by (Fardal, 2006) identified other reasons for non-compliance: patients were seeing a general dentist for SPC while not being compliant with the appointments at the specialist clinic. This may be due to the lack of awareness and knowledge of the patient and the general dentist regarding the importance of specialist care for maintenance postperiodontal active therapy. There is evidence that patients who, after completing a course of periodontal therapy return to the care of general dentists, do not do as well in terms of periodontal stability as the patients who continue with a specialist maintenance programme (Axelsson \& Lindhe, 1981; Cohen et al., 2003; Leavy \& Robertson, 2018). Similarly, several studies have also reported non-compliance with oral selfhealth-care recommendations (Macgregor et al., 1998; Mohd-Dom et al., 2009).

To our knowledge, no studies in these areas have focused on a periodontal patient under the SPC. Most studies were only targeting the general population or a periodontal patient during the active phase of treatment (Martensson et al., 2013; Raman, 2012). There is no apparent reason for this, but we can speculate that it may be because we perceive patients who have been under specialist care to be adequately motivated and to possess an adequate level of knowledge. However, from previous studies, it has been shown that a high percentage of patients who were treated in a specialist clinic failed to follow the recommendation by the specialist (Delatola et al., 2014; Ojima et al., 2001). We assumed this was related to the patient's level of knowledge and awareness, which declines over time once they enter the SPC, or maybe the information given to the patient was not sufficient or specific enough according to their periodontal problem. Therefore, this study aims to investigate the baseline knowledge and behaviour of periodontal patients under SPC concerning their periodontal health.

\section{Methods}

\section{Study location and data collection}

The study was based on a self-response questionnaire. The questionnaire consisted of three domains and 19-items developed and modified based on questions drawn from a review of literatures (Ahmad N.A. et al., 2018; Mohd-Dom et al., 2009; Raman, 2012; Varela-Centelles et al., 2016). The domains include items related to periodontal and oral health perception, periodontal knowledge, and behaviours. Four questions were used to evaluate the patient's perception of their periodontal 
health. Seven statements were used for assessing the knowledge of periodontitis, focusing on aetiology, symptoms, treatment, and maintenance. The last section of the questionnaire was on oral health behaviour, consisting of the frequency of tooth brushing, frequency of interdental cleaning, the type of interdental cleaning aid used, and other oral cleaning aid. Also, four statements were used to evaluate the patient's thoughts on their current oral health practices.

The questions were initially written in English and later translated by a local interpreter to ensure the questionnaire's validity. It was then successively translated back to English by a second interpreter to avoid interpretation mistakes. The questionnaire was reviewed for content validity by two dental experts (periodontist A.A and senior dentist C.H.L), using a 4points Likert scale. Verbal comments and recommendations were made to improve the relevance of the items. Based on the content validation calculation, all 19-items had achieved a satisfactory level, with a universal agreement index (S-CVI/UA) and an average index (S-CVI/AG) of 1.0 for all three domains. Pre-tested for face-validity was conducted on 20 patients. For each question, the patient may only choose one answer (except for the first part of the behaviour section) from all possible responses provided in the questionnaire. The scale of 1-5 indicates; No (1-2), Don't know or neutral (3), and Yes (4-5). An answer will be scored as incorrect when none of the correct responses or neutral (scale 3) was chosen. Assistance was rendered if they could not read due to vision impairment or for any clarification during the questionnaire's completion. Due to a small study population, the sample size was calculated using a formula of $\mathrm{n}=\mathrm{Nz}^{2} \mathrm{p}(1$ $\mathrm{p}) /\left[\mathrm{d}^{2}(\mathrm{~N}-1)+\mathrm{Z}^{2} \mathrm{p}(1-\mathrm{p})\right]$ where $(\mathrm{N}$ is the population size of 100 based on 2018 data of two periodontic clinics in Sarawak), (z values is 1.96 as the confidence level is $95 \%$ ), ( $\mathrm{p}$ is the prevalence which is $50 \%$ ), and ( $\mathrm{d}$ is the proportion of sampling error of 0.05), which is at least 80 participants.

The questionnaire was distributed to all adult patients diagnosed with periodontitis
(Armitage, 1999) who have just completed active periodontal therapy and were under SPC in 2019. The survey was conducted at two different periodontology clinics, one in Kuching (Unit Pakar Periodontik Jalan Masjid) and another in Sibu (Unit Pakar Periodontik Sibu Jaya) during the period from June to December 2019. The patients were given written information about the study, how the sample was selected, and how they could be given further details. Written consent was obtained from all participants in this study. The study was registered with the National Medical Research Register, Ministry of Health Malaysia -NMRR-183844-43984 (IIR) and approved by the Medical Research \& Ethics Committee (MREC), Ministry of Health Malaysia.

\section{Data analysis}

Data were analysed using IBM SPSS Statistics for Window, version 23 (IBM Corp., Armonk, N.Y., USA). Frequency distribution and percentage to analyse the level of periodontal health knowledge and behaviour of patients.

\section{Results}

A total of 80 questionnaires were completed from the Periodontal Specialist Units of Jalan Masjid and Sibu Jaya. As shown in Table 1, the majority of them were $>50$ years old. More female (61.2\%) respondents when compared to male (38.8\%). For the educational level, the majority of them were from the tertiary level (56.2\%). There were more respondents who needed to travel $\geq 10$ $\mathrm{km}(47.5 \%)$, followed by 5 - 9km (31.3\%) and $\leq 4 \mathrm{~km}(21.2 \%)$.

More than half of the respondents rated their general health as good-excellent (68.8\%), but $55 \%$ of them believed that their oral health was in a poor-fair condition. In terms of periodontal health, only $31.3 \%$ of adults believed that they had a good-excellent level of periodontal health, and $41.3 \%$ of them felt satisfied with their current periodontal condition (Table 2). 
The majority of participants correctly defined the meaning of dental plaque $(81.3 \%)$ and did know its role in the aetiology of the gingival disease $(92.5 \%)$. They were aware that gingival bleeding indicated the presence of periodontal disease (91.3\%), which can lead to mobile teeth if untreated (91.3\%), and that it can be prevented by having good oral hygiene (93.8\%). They were also aware of the importance of regular maintenance therapy to prevent periodontal disease recurrence (91.3\%). However, less than half $(45 \%)$ of the participants were aware that the disease is not 'curable.' (Table 3).
$98.8 \%$ of the respondents brushed their teeth at least twice a day. Only $43.7 \%$ of the respondents regularly used dental floss, but more of them used an interdental brush $(65 \%)$, and $52.5 \%$ of them used a mouth rinse as part of their oral care regime (Table 4).

For gingival bleeding, $70 \%$ of them disagreed with avoiding brushing, and $63.7 \%$ disagreed with using an only mouth rinse. $62.5 \%$ of the participants agreed not to skip a periodontal appointment, even if they had no pain symptoms, with $38.8 \%$ who believed that periodontal maintenance could be solely provided by a general dentist (Table 5).

Table 1. Socio-demographic profiles of the participants.

$\begin{array}{llr}\text { Demographic categories } & & \text { n (\%) } \\ \text { Age } & <20 \text { years } & 0(0) \\ & 20-30 \text { years } & 4(5) \\ & 31-40 \text { years } & 20(25) \\ & 41-50 \text { years } & 17(21.3) \\ \text { Gender } & >50 \text { years } & 39(48.7) \\ & \text { Male } & 31(38.8) \\ \text { Education level } & \text { Female } & 49(61.2) \\ & \text { No formal education } & 2(2.5) \\ & \text { Primary } & 2(2.5) \\ \text { Distance from the specialist clinic } & \text { Secondary } & 31(38.8) \\ & \text { Tertiary } & 45(56.2) \\ & \leq 4 \mathrm{~km} & 17(21.2) \\ & 5-9 \mathrm{~km} & 25(31.3) \\ & \geq 10 \mathrm{~km} & 38(47.5)\end{array}$

Table 2. Percentage distributions of the respondents on the general and periodontal health perception.

1. How would you rate your general health condition?

2. How would you rate your oral health condition?

3. How would you rate your gum health condition?

4. Are you satisfied with your gum health?

Good-Excellent (\%) Poor-Fair (\%)

55 (68.8)
$36(45.0)$
$25(31.3)$
$33(41.3)$
47 (58.7)

Table 3. Percentage distributions of the respondents on the level of periodontal knowledge.

$\begin{array}{lll}\text { 1. Dental plaque means soft debris on the teeth. } & \begin{array}{l}\text { Correct } \\ \text { answer (\%) }\end{array} & \begin{array}{l}\text { Incorrect } \\ \text { Answer (\%) }\end{array} \\ \text { 2. Dental plaque can lead to gum disease. } & 65(81.3) & 15(18.7) \\ \text { 3. Gum bleeding is an early sign of gum disease. } & 74(92.5) & 6(7.5) \\ \text { 4. Untreated gum disease may cause teeth to become loose. } & 73(91.3) & 7(8.7) \\ \text { 5. Proper oral hygiene can control dental plaque formation. } & 73(91.3) & 7(8.7) \\ \text { 6. Periodontitis (severe gum disease) is not curable. } & 36(45.0) & 5(6.2) \\ \text { 7. Regular check-up for maintenance therapy can } & 73(91.3) & 44(55.0) \\ \text { prevent recurrence of gum disease. } & & 7(8.7)\end{array}$


Table 4. Percentage distributions of the respondents on oral health practices.

$\begin{array}{llllll} & \begin{array}{l}\text { 1/day } \\ (\%)\end{array} & \begin{array}{l}\text { 2-3/day } \\ (\%)\end{array} & \begin{array}{l}\text { When needed } \\ (\%)\end{array} & \begin{array}{l}\text { Don't use } \\ (\%)\end{array} & \begin{array}{l}\text { Don't know } \\ (\%)\end{array} \\ \text { Toothbrush } & 1(1.2) & 79(98.8) & 0(0.0) & 0(0.0) & 0(0.0) \\ \text { Dental Floss } & 22(27.4) & 13(16.3) & 27(33.8) & 16(20.0) & 2(2.5) \\ \text { Interdental brush } & 38(47.5) & 14(17.5) & 16(20.0) & 10(12.5) & 2(2.5) \\ \text { Mouth wash } & 42(52.5) & 0(0.0) & 0(0.0) & 38(47.5) & 0(0.0)\end{array}$

Table 5. Percentage distributions on the beliefs the respondents had concerning their current periodontal practices.

$\begin{array}{lll} & \text { Agree (\%) } & \text { Disagree (\%) } \\ \text { 1. I avoid brushing when my gums bleed. } & 24(30.0) & 56(70.0) \\ \text { 2. I use only mouth rinse if my gums bleed. } & 29(36.3) & 51(63.7) \\ \text { 3. I skip my appointment with the gum specialist if there is no pain. } & 30(37.5) & 50(62.5) \\ \text { 4. I think I can just visit any general dentist for my gum } & 31(38.8) & 49(61.2) \\ \text { maintenance therapy. } & & \end{array}$

\section{Discussion}

This study found that less than half (41.3\%) of the respondents were satisfied with their current periodontal condition, with only $31.3 \%$ rated as having good to an excellent level of oral health. As most of the periodontal referral cases to the specialist clinic were at the advanced stage of severity, it was expected. Several studies have shown that the greater the severity of the disease, the greater the impact on the quality of life of an individual (Graziani \&Tsakos, 2020; Masood et al., 2019). Therefore, the importance of early detection and referral for periodontal treatment at the moderate stage should be emphasised among dentists at primary care.

Although periodontal disease can be controlled by proper treatment, more than half $(55 \%)$ of the respondents were not aware that it 'uncurable'. Such findings may be real or might be related to interpretation errors in this survey. For example, respondents may think that their periodontal condition has been cured as they are not experiencing any significant symptoms of periodontitis such as bleeding, swelling, or pain as they are now under the maintenance phase. However, what they are having right now is a stable stage, which may recur at any time, especially with poor home and professional maintenance care. This misconception or false belief resulting from a lack of knowledge is a significant barrier in the way of proper management of periodontitis (Deinzer et al., 2009). The majority of respondents answered the rest of the knowledge questions correctly.

Knowledge of periodontal disease may influence patients' behaviour and practices (Deinzer et al., 2009). However, the link between these two was not evaluated in this study. Still, some behaviour and oral health practices among respondents seemed to correlate with their knowledge level. 98.8\% of the respondents reported a toothbrushing frequency of twice or more per day. The use of interdental brush was also found to be encouraging at $65 \%$. This is very high compared to other studies, whereby their studies reported $6.9 \%$ and $20.4 \%$ of their respondents with interdental brush usage, respectively (Badiah, 2015; Lee et al., 2019). This can be due to the advice given on interdental brush instead of floss, as more spacing between teeth can be found in periodontitis cases. It was found that both periodontal specialist clinics in Kuching and Sibu did provide interdental brush to their patients. Surprisingly, $30 \%$ of the respondents gave up tooth brushing when they experienced gingival bleeding, and $36.3 \%$ will replace tooth brushing with mouth rinses. This information indicates a lack of correlation between knowledge and behaviour in gingivitis, which requires further reemphasising among periodontal patients at the SPC.

The periodontal health stability is related to the balance between oral hygiene performed 
by the patient at home and professional cleaning provided at regular follow-up during SPC (Axelsson et al., 2004; Tonetti et al., 1998). The majority of the respondents agreed that regular check-ups at SPC could prevent periodontitis's recurrence (91.3\%). However, $37.5 \%$ of the respondents stated that they would only visit the periodontal clinic when having a pain symptom. Some of the respondents (38.8\%) believed that the general dentist could carry out adequate SPC. These may contribute to the noncompliance attendance at SPC, leading to disease recurrence (Fardal, 2006). This suggests that the respondents may need further information regarding the importance of regular visits for SPC.

There are several limitations in this present study. Evidence showed that the longer the duration of periodontal maintenance could result in poor attendance and compliance for SPC due to low motivation level (Demetriou et al., 1995). The motivation usually links with the knowledge and awareness status of the patient (Shiva et al., 2017). But, this association cannot be evaluated because no assessment was done on the duration of SPC among respondence in this study. However, (De Carvalho V.F. et al., 2010) found a significant improvement in compliance toward SPC for a patient with poor attendance after reinforcing the knowledge of periodontitis. Another limitation is the small sample size, which may affect the reliability of the results. Moreover, the results were based on two periodontal clinics within the State of Sarawak, which may possess socioeconomic and cultural differences from other states in Malaysia. The questions are also done among patients diagnosed with either chronic or aggressive periodontitis, which cannot be generalised to the different types of periodontal diseases or conditions.

\section{Conclusion}

Within the limitation of this study, it can be concluded that a high level in periodontal knowledge and behaviour was found among periodontal patients in SPC. However, the respondents showed a low level of knowledge of periodontitis's curative nature and a low level of desired behaviour in practising when they experienced with bleeding gingiva. As some of the respondents lack understanding of the importance of regular follow-ups provided by specialist care, this may further contribute to the risk of non-compliance. It is important to reinforcing oral health education to boost patient motivation toward maintaining good periodontal health at SPC. Further study is required to explore any correlation between the level of knowledge and behaviour towards SPC compliance. A multi-centre study should be considered, so a larger sample size can be obtained involving other states in Malaysia to get a more significant result.

\section{Acknowledgements}

The authors would like to thank the Director-General of Health Malaysia for permission to publish this paper. We are also indebted to Dr. Thaddius Herman, Dental Public Health Specialist, and the heads of departments in the Dental Division of Kuching and Sibu for giving us the permission and support to conduct this study.

\section{Conflict of interest}

The authors declare no conflict of interest.

\section{References}

Ahmad N.A., Naime Z., Maling T.H. , Lo, J. Y. Y. (2018). The beliefs and oral health practices amongst indigenous people in bario, sarawak (unpublished manuscript). University of Malaya, Malaysia.

Armitage, G. C. (1999). Development of a classification system for periodontal diseases and conditions. Annals of Periodontology, 4(1), 1-6.

Axelsson, P., Lindhe, J. (1981). Effect of controlled oral hygiene procedures on caries and periodontal disease in adults. Results after 6 years. Journal of Clinical Periodontology, 8(3), 239-248.

Axelsson, P., Nystrom, B. , Lindhe, J. (2004). The longterm effect of a plaque control program on tooth mortality, caries and periodontal disease in adults. Results after 30 years of maintenance. Journal of Clinical Periodontology, 31(9), 749-757.

Badiah, H. (2015). A preliminary survey on awareness of periodontal risk and oral health practices among diabetic patients in hospital kuala. Malaysian Dental Journal, 34(1), 1-7. 
Cohen, R. E., Research, Science Therapy Committee , American Academy of Periodontology. (2003). Position paper: Periodontal maintenance. Journal of Periodontology, 74(9), 1395-1401.

de Carvalho V.F., Okuda O.S., Bernardo C.C., Pannuti C.M., Georgetti M.A., De Micheli G., et al. (2010). Compliance improvement in periodontal maintenance. Journal of Applied Oral Science, 18(3), 215-219.

Deinzer, R., Micheelis, W., Granrath, N. , Hoffmann, T. (2009). More to learn about: Periodontitis-related knowledge and its relationship with periodontal health behaviour. Journal of Clinical Periodontology, 36(9), 756-764.

Delatola, C., Adonogianaki, E. , Ioannidou, E. (2014). Non-surgical and supportive periodontal therapy: Predictors of compliance. Journal of Clinical Periodontology, 41(8), 791-796.

Demetriou, N., Tsami-Pandi, A. , Parashis, A. (1995). Compliance with supportive periodontal treatment in private periodontal practice. A 14year retrospective study. Journal of Periodontology, 66(2), 145-149.

Fardal, 0. (2006). Interviews and assessments of returning non-compliant periodontal maintenance patients. Journal of Clinical Periodontology, 33(3), 216-220.

Graziani, F. , Tsakos, G. (2020). Patient-based outcomes and quality of life. Periodontology 2000, 83(1), 277-294.

Jackson, M. A., Kellett, M., Worthington, H. V. , Clerehugh, V. (2006). Comparison of interdental cleaning methods: A randomized controlled trial. Journal of Periodontology, 77(8), 1421-1429.

Kopp, S. L., Ramseier, C. A., Ratka-Kruger, P. , Woelber, J. P. (2017). Motivational interviewing as an adjunct to periodontal therapy-a systematic review. Frontiers in Psychology, 2017(8), 279.

Leavy, P. G. , Robertson, D. P. (2018). Periodontal maintenance following active specialist treatment: Should patients stay put or return to primary dental care for continuing care? A comparison of outcomes based on the literature. International Journal of Dental Hygiene, 16(1), 6877.

Lee, J. Y., Park, H. J., Lee, H. J. , Cho, H. J. (2019). The use of an interdental brush mitigates periodontal health inequalities: The korean national health and nutrition examination survey (KNHANES). BMC Oral Health, 19(1), 168.

Linden, G. J., Lyons, A. , Scannapieco, F. A. (2013). Periodontal systemic associations: Review of the evidence. Journal of Periodontology, 84(4 Suppl), S8-S19.

Macgregor, I. D., Balding, J. W. , Regis, D. (1998). Flossing behaviour in english adolescents. Journal of Clinical Periodontology, 25(4), 291-296.

Martensson, C., Soderfeldt, B., Axtelius, B. , Andersson, P. (2013). Knowledge of periodontitis and selfperceived oral health: A survey of periodontal specialist patients. Swedish Dental Journal 37(1), 49-58.

Masood, M., Younis, L. T., Masood, Y., Bakri, N. N. , Christian, B. (2019). Relationship of periodontal disease and domains of oral health-related quality of life. Journal of Clinical Periodontology, 46(2), 170-180.

Mohd Dom, T. N., Ayob, R., Abd Muttalib, K. , Aljunid, S. M. (2016). National economic burden associated with management of periodontitis in malaysia. International Journal of Dentistry, 2016(1891074), 1-6.

Mohd-Dom, T. N., S. M. Said , Abidin, Z. Z. (2009). Dental knowledge and self-reported oral care practices among medical, pharmacy and nursing students Malaysian Journal of Health Science, 7(1), 13-23.

Ojima, M., Hanioka, T. , Shizukuishi, S. (2001). Survival analysis for degree of compliance with supportive periodontal therapy. Journal of Clinical Periodontology, 28(12), 1091-1095.

Petersen, P. E. , Ogawa, H. (2005). Strengthening the prevention of periodontal disease: The who approach. Journal of Periodontology, 76(12), 2187-2193.

Raman, R. W., Woon, T. K.; Mamat, M.; Ishak, A.; Khan, A. R. (2012). Oral health awareness, behaviour and status among malaysian 16-year-old school students in penang. Malaysian Dental Journal, 34 (2), 45-53.

Shiva, C. Y. K., Mukta, V. S. , Vinay, K. M. (2017). Patient education and motivation. Advances in Dentistry \& Oral Health, 7(1), 28-33.

Slots, J. (2017). Periodontitis: Facts, fallacies and the future. Periodontology 2000, 75(1), 7-23.

Tonetti, M. S., Muller-Campanile, V., Lang, N. P. (1998). Changes in the prevalence of residual pockets and tooth loss in treated periodontal patients during a supportive maintenance care program. Journal of Clinical Periodontology, 25(12), 1008-1016.

Varela-Centelles, P., Diz-Iglesias, P., Estany-Gestal, A., Seoane-Romero, J. M., Bugarin-Gonzalez, R. , Seoane, J. (2016). Periodontitis awareness amongst the general public: A critical systematic review to identify gaps of knowledge. Journal of Periodontology, 87(4), 403-415.

Yaacob, M., Worthington, H. V., Deacon, S. A., Deery, C., Walmsley, A. D., Robinson, P. G., et al. (2014). Powered versus manual toothbrushing for oral health. Cochrane Database of Systematic Reviews, 2014(6), Art. No. CD002281. 